\title{
Adsorption Removal of Pollutant Dyes in Wastewater by Nitrogen-doped Porous Carbons Derived from Natural Leaves
}

\author{
Jun Chen ${ }^{1}$, Xiaosu Wang ${ }^{1}$, Yan Huang ${ }^{1 *}$, Shanshan $\mathrm{Lv}^{1 *}$, Xiaohua Cao ${ }^{3}$, Jimmy Yun ${ }^{4}$ and Dapeng $\mathrm{Cao}^{1,23^{*}}$
}

An easy pyrolysis and activation synthesis method has been proposed to convert a common biomass waste of Euonymus japonicus leaves into nitrogen-doped porous carbons (NPCs), and its application in the removal of methylene blue (MB), methylene orange (MO) and rhodamine B $(\mathrm{RhB})$ from simulated wastewater was further explored. The uptake of NPCs for dyes increases along with the initial dye concentration and contact time but decreases with the NPC dosage. The adsorption capacities of the NPCs for MB, RhB and MO were $626.1,620.7$ and 370.8 $\mathrm{mg} \cdot \mathrm{g}^{-1}$, respectively, which meant that the NPCs were better adsorbents for cationic dyes (MB and RhB), compared to the anionic dye (MO), because the NPC surfaces carry partial negative charges. In order to elaborate the adsorption mechanism, the kinetics data were analyzed by pseudo-first order, pseudo-second order, intra-particle diffusion and Elovich models, in which the pseudo-second order model exhibited the best fit. The adsorption data were evaluated by Langmuir, Freundlich, Temkin and Dubinin-Radushkevich isotherm models, in which the Langmuir model could well describe the adsorption processes. This study presented a potential alternative low-cost high efficient adsorbent for removing pollutant dyes from wastewater through using biomass waste leaves as sources.

Keywords: Pollutant dyes; Wastewater treatment; Nitrogen-doped porous carbons; Leaves; Biomass waste processing

Received 16 November 2018, Accepted 13 December 2018

DOI: $10.30919 / \mathrm{es} 8 \mathrm{~d} 666$

\section{Introduction}

Dyes as the main component of organic pollutants in wastewater have been of particular environmental concerns due to their harmful effects on many forms of life. ${ }^{1}$ Dyes are known to cause serious ecological problems such as inhibition of benthic photosynthesis and carcinogenicity, as well as generating dangerous compounds through oxidation, hydrolysis and other chemical reactions. In addition, most of synthetic dyes are biologically non-degradable. Therefore, it is greatly demanded to develop high performance materials for removal of dyes from wastewater. ${ }^{2,3}$ Currently, main pollutant dyes contain methylene blue (MB), rhodamine $\mathrm{B}(\mathrm{RhB})$ and methylene orange (MO). $\mathrm{MB}$ is an aromatic heterocyclic cationic dye. $\mathrm{MB}$ is commonly used in textile industry to confer a dark green color, and is often considered as a model dye system for research purposes. $\mathrm{RhB}$ is a synthetic cationic dye with a fresh pink color, and is widely used in printing and dyeing industries. Meanwhile, MO is an anionic dye with an orange-yellow color, and is

${ }^{1}$ State Key Laboratory of Organic-Inorganic Composite Materials, Beijing University of Chemical Technology, Beijing 100029, P. R. China ${ }^{2}$ Beijing Advanced Innovation Center for Soft Matter Science and Engineering, Beijing University of Chemical Technology, Beijing 100029, P. R. China

${ }^{3}$ College of Chemical and Environmental Engineering, Jiujiang University, Jiujiang, Jiangxi 332005, P. R. China

${ }^{4}$ School of Chemical Science and Engineering, The University of New South Wales, Sydney, NSW 2052, Australia

*E-mail: huangyan@mail.buct.edu.cn; lvshanshan@mail.buct.edu.cn; caodp@mail.buct.edu.cn widely used as indicators in acid-base titration experiments. There have been several techniques available such as adsorption, chemical oxidation, coagulation/flocculation, membrane separation/filtration, reverse osmosis, ion exchange resins, precipitation, evaporation, Fentonbiological treatment (through aerobic and anaerobic degradation using various microorganisms), sonochemical degradation, electrochemical treatment and photocatalytic degradation. ${ }^{48}$

Among these techniques, adsorption has been proven to be the most competitive method owing to its high efficiency, simplicity of design, ease of operation and implementation, economic feasibility, low energy consumption and non-toxicity. ${ }^{9-11}$ The adsorption technique is based on the transfer of pollutants from a solution to a solid phase, that is, an absorbent. ${ }^{12-14}$ In selection of the adsorbents, the main criteria are cost effectiveness, availability and adsorptive properties, as well as high surface area and reactive surface atom. ${ }^{12}$ Among various adsorbents, biomass-derived carbons are most wildly due to their distinctive porous structures, surface properties, large surface area, low density, chemical inertness and high adsorption capacity, ${ }^{15-17}$ where these biomasses contain coconut husk,$^{18}$ cocoa shell, ${ }^{19}$ bamboo fibers, ${ }^{20}$ orange peel, ${ }^{21}$ palm shell, ${ }^{22}$ walnut shell, ${ }^{23}$ coffee grounds, ${ }^{24}$ coffee husk, ${ }^{25}$ rice husk and saw dust. ${ }^{26}$

The advantage of using biomass (waste) as raw materials to prepare porous carbons is that these raw materials are renewable and sustainable. ${ }^{27}$ Therefore, it is easy to produce cheap porous carbons from natural abundant and eco-friendly sources ${ }^{28}$. However, the effectiveness and usability are still hindered by certain limitations. As the obtained porous carbons depend on the type of biomass and preparation method, it is significant to consider alternative types of biomass as raw materials for synthesis of efficient absorbents. Motivated by these attempts, this study aims to explore the synthesis of porous carbons based on Euonymus japonicus leaves, a kind of common biomass waste, and the 
feasibility of using the resultant porous carbons as adsorbents for removal of dyes from a simulated wastewater. Three types of dyes, MB, $\mathrm{MO}$ and $\mathrm{RhB}$, were investigated. The effects of the contact time, initial dye concentration and adsorbent dosage on the adsorption processes were examined. The thermodynamics and kinetics adsorption data were also evaluated to elaborate the adsorption mechanisms.

\section{Materials and methods}

\subsection{General}

Methylene blue (MB, MW 319.86), methylene orange (MO, MW 327.33) and Rhodamine B (RhB, MW 479.01) were purchased from Sigma-Aldrich. Potassium hydroxide and hydrochloric acid were purchased from Sigma-Aldrich. All the chemicals and reagents were analytical grade, and used as received without further purification. Deionized water was used for all the experiments.

\subsection{Synthesis of nitrogen-doped porous carbons (NPCs)}

Briefly, Euonymus japonicus leaves were washed with water to remove dust and other impurities, and then dried at $60{ }^{\circ} \mathrm{C}$ for $24 \mathrm{~h}$. The leaves were ground and passed through a 50-mesh sieve to obtain powders. $\sim 3 \mathrm{~g}$ of the powder was pyrolyzed/ carbonized in a tubular furnace under nitrogen atmosphere $\left(200{ }^{\circ} \mathrm{C}\right.$ for $1 \mathrm{~h}$, and then up to $800{ }^{\circ} \mathrm{C}$ for $2 \mathrm{~h}$ ). The heating procedure was started at room temperature and increased at a rate of $5{ }^{\circ} \mathrm{C} \cdot \mathrm{min}^{-1}$. At the end of the procedure, the reactor was cooled down to room temperature. Subsequently, the remained powder was mixed with potassium hydroxide at a ratio of $1: 2$, and further activated at $800{ }^{\circ} \mathrm{C}$ for $1 \mathrm{~h}$. The obtained mixture was washed by hydrochloric acid several times and water thoroughly until no chloride, and collected after drying under vacuum.

\subsection{Characterization of the NPCs}

Scanning electron microscopy (SEM): The surface topography and morphology structure of the NPCs were analyzed by a Hitachi S-4800 scanning electron microscope operated at an acceleration voltage of $20 \mathrm{kV}$. Nitrogen adsorption-desorption isotherms: The specific surface area, pore volume and pore size distribution of the NPCs were measured by a nitrogen adsorption-desorption cycling method using a Physisorption Analyzer (Micromeritics ASAP 2020, USA). The external mesoporous and macroporous surface area was calculated by difference of the Brunauer-Emmett-Teller (BET) surface area and the microporous surface area. All samples were degassed under vacuum at $300{ }^{\circ} \mathrm{C}$ for 4 $\mathrm{h}$ at a pressure of less than $5 \times 10^{-3}$ Torr.

Elemental analysis: The type and relative contents of elements in the NPCs were measured by elemental analysis. The qualitative elemental compositions of the NPCs were also analyzed using a ThermoFisher ESCALAB 250 X-ray photoelectron spectroscopy (XPS) with a Mg Ka source.

Raman spectroscopy: The Raman spectra were recorded using a Via reflecting unit of an Ar-Ion laser having an excitation wavelength of $514 \mathrm{~nm}$ (Instrument model: HORIBA Jobin Yvon). The molecular structure was determined by analyzing the change in the spectral frequency caused by molecular vibration.

Fourier Transform Infrared (FTIR) spectroscopy: The surface functional groups of the NPCs were investigated by an FTIR spectrometer (Bruker AC-80MHZ, USA) in the transmission mode in the range from 400 to $4000 \mathrm{~cm}^{-1}$ with a resolution of $4 \mathrm{~cm}^{-1}$. For each test, the sample was mixed with $\mathrm{KBr}$ and compressed to form disks.

UV-Vis spectroscopy: The absorbance of dyes at the maximum absorption wavelength was measured using a Tu-1901 UV spectrometer, and used for quantitative calculation of dye concentrations. The maximum absorption wavelengths of $\mathrm{MB}, \mathrm{MO}$ and $\mathrm{RhB}$ were 665,464 and $554 \mathrm{~nm}$, respectively.

\subsection{Adsorption measurement and analysis}

The simulated wastewater containing dyes at $1000 \mathrm{mg} \cdot \mathrm{L}^{-1}$ was prepared as stock solutions. In a typical experiment, adsorption experiments were carried out by shaking $20 \mathrm{mg}$ of the NPCs in $100 \mathrm{~mL}$ of dye solutions with an initial concentration of $100 \mathrm{mg} \cdot \mathrm{L}^{-1}$ at a speed of $300 \mathrm{rpm}$ at $25^{\circ} \mathrm{C}$. The effects of adsorbent dosage, contact time and initial dye concentration on the adsorption processes were studied. The performance of the NPCs was evaluated by adsorption capacity of the adsorbent and removal efficiency of the dyes following equations listed as below,

$$
\begin{aligned}
\mathrm{q}_{t} & =\frac{c_{i}-c_{t}}{M} \\
\text { Removal } \% & =\frac{c_{i}-c_{t}}{c_{i}} \times 100 \%
\end{aligned}
$$

where $c_{i}$ represents the initial dye concentration and $c_{t}$ represents the dye concentration at time $t\left(\mathrm{mg} \cdot \mathrm{L}^{-1}\right), M$ represents the amount of the adsorbent added in per liter dye solution $\left(\mathrm{g} \cdot \mathrm{L}^{-1}\right)$ and $q_{t}$, the adsorption capacity, represents the amount of dyes adsorbed on per gram adsorbent at time $t\left(\mathrm{mg} \cdot \mathrm{g}^{-1}\right)$.

The kinetics and thermodynamics of the adsorption processes were further explored. Four kinetics models were examined and given $b^{29}$ Pseudo-first order model:

$$
\ln \left(q_{e}-q_{t}\right)=\ln q_{e}-k_{1} t
$$

Pseudo-second order model:

$$
\frac{t}{q_{t}}=\frac{t}{q_{e}}+\frac{1}{k_{2} q_{e}^{2}}
$$

Intra-particle diffusion model:

$$
q_{t}=k_{i d} t^{0.5}+c
$$

Elovich model:

$$
q_{t}=\frac{1}{\beta} \ln (\alpha \beta)+\frac{1}{\beta} \ln t
$$

Four isotherm models were used and given by ${ }^{30}$ Langmuir model:

$$
\frac{c_{e}}{q_{e}}=\frac{c_{e}}{q_{m}}+\frac{1}{q_{m} k_{L}}
$$

Freundlich model:

$$
\ln q_{e}=\ln K_{F}+\frac{1}{n} \ln c_{e}
$$

Temkin model:

$$
q_{e}=\frac{R T}{b_{t}} \ln \alpha_{t}+\frac{R T}{b_{t}} \ln c_{e}
$$

Dubinin-Radushkevich model:

$$
\begin{gathered}
\ln q_{e}=\ln Q_{m}-B \varepsilon^{2} \\
\varepsilon^{2}=R \operatorname{Rln}\left(1+\frac{1}{c_{e}}\right)
\end{gathered}
$$


where $k_{1}\left(\mathrm{~min}^{-1}\right)$ and $k_{2}\left(\mathrm{~g} \cdot \mathrm{mg}^{-1} \cdot \mathrm{min}^{-1}\right)$ represent the rate constant of pseudo-first order and pseudo-second order adsorption, respectively; $k_{i d}$ $\left(\mathrm{g} \cdot \mathrm{mg}^{-1} \cdot \mathrm{min}^{0.5}\right)$ and $c$ represent the intra-particle diffusion rate constant and the intercept, respectively; $\alpha\left(\mathrm{g} \cdot \mathrm{mg}^{-1}\right)$ and $\beta\left(\mathrm{g} \cdot \mathrm{mg}^{-1} \cdot \mathrm{min}\right)$ represent the initial adsorption rate and desorption constant of the Elovich model; $q_{m}$ represents the maximum amount of adsorbed dye, $q_{e}$ and $q_{t}\left(\mathrm{mg} \cdot \mathrm{g}^{-1}\right)$ represent the amount of dye adsorbed at equilibrium and at time t, respectively, $K_{L}$ represents the Langmuir constant; $K_{F}$ represents the Freundlich constant; $R$ represents the ideal gas constant, $T$ represents the absolute temperature during the adsorption process, $\alpha_{t}$ and $b_{t}$ represent the Temkin constant; $B$ represents the Dubinin-Radushkevich constant, and $\varepsilon$ represents the Polanyi adsorption potential.

\section{Results and discussion}

\subsection{Synthesis and characterization of nitrogen-doped porous carbons (NPCs)}

The synthesis of porous carbons derived from the Euonymus japonicus leaves contains two steps, i.e., carbonization and activation. Carbonization of the raw materials (dried leaves) were performed at a high temperature under nitrogen atmosphere to remove noncarbonaceous components, and then activation was carried out to produce porous structures and large surface areas of the resultant materials (NPCs). The NPCs were further utilized in adsorption of three types of dyes from a simulated wastewater. Schematic representation of the process was shown in Fig. 1.
Scanning electron microscopy (SEM) has been a primary tool for characterizing morphology of various adsorbents. SEM images showed that the NPCs exhibited hollow, thin-walled and flake-like structures (Fig. 2a, b). Formation of the pores might be caused during the carbonization step by decomposition of cellulose, hemicellulose and lignin in the leaves, generating volatile gases. The formation of the micropores might also be caused during the chemical activation step by potassium hydroxide. $^{31}$

$$
\begin{aligned}
& 6 \mathrm{KOH}+2 \mathrm{C} \rightarrow 2 \mathrm{~K}+2 \mathrm{~K}_{2} \mathrm{CO}_{3}+3 \mathrm{H}_{2} \uparrow \\
& 4 \mathrm{KOH}+\mathrm{C} \rightarrow \mathrm{K}_{2} \mathrm{CO}_{3}+\mathrm{K}_{2} \mathrm{O}+2 \mathrm{H}_{2} \uparrow
\end{aligned}
$$

In order to characterize the porous structures of the NPCs, nitrogen adsorption-desorption measurements were conducted (Fig. 2c). The adsorption isotherm of the NPCs exhibited apparent hysteresis loop, indicating existence of significant amount of micropores and mesopores. ${ }^{32}$ The Brunauer-Emmett-Teller (BET) specific surface area of the NPCs was calculated to be $1854.06 \mathrm{~m}^{2} \cdot \mathrm{g}^{-1}$. More porosity parameters were listed in Table 1.

Good dye adsorption performance of porous carbons is often a result of their large surface area, microporous structure, and high level surface activities. ${ }^{33}$ It has been reported that addition of heteroatoms into carbon materials can significantly improve performance of carbon materials, since the presence of heteroatoms could lead to redistribution

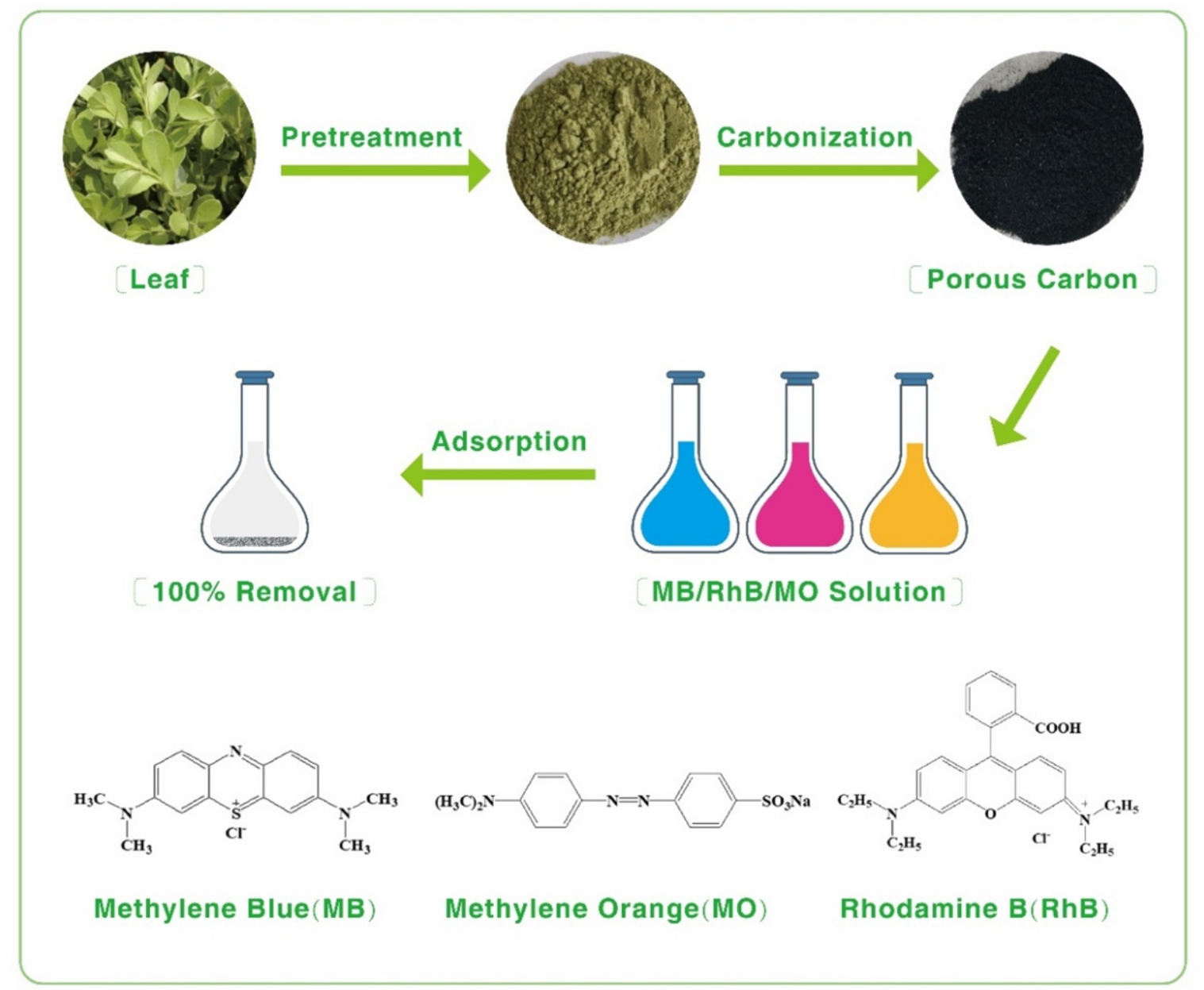

Fig. 1 Schematic representation of the preparation and application of nitrogen-doped porous carbons (NPCs). Leaves were used as precursors to prepare the NPCs. The NPCs were further utilized in adsorption of cationic dyes (MB and RhB) and an anionic dye (MO) from simulated wastewater. 
Table 1 Porosity parameters of the NPCs.

\begin{tabular}{llllll}
\hline $\mathrm{S}_{\mathrm{BET}}{ }^{\mathrm{a}}\left(\mathrm{m}^{2} \cdot \mathrm{g}^{-1}\right)$ & $\mathrm{S}_{\text {Langmuir }}\left(\mathrm{m}^{2} \cdot \mathrm{g}^{-1}\right)$ & $\mathrm{V}_{\mathrm{t}}^{\mathrm{b}}\left(\mathrm{cm}^{3} \cdot \mathrm{g}^{-1}\right)$ & $\mathrm{V}_{\text {micro }}{ }^{\mathrm{c}}\left(\mathrm{m}^{2} \cdot \mathrm{g}^{-1}\right)$ & $\mathrm{V}_{\text {micro }} / \mathrm{V}_{\mathrm{t}}(\%)$ & $\mathrm{D}_{\mathrm{HK}}{ }^{\mathrm{d}}(\mathrm{nm})$ \\
\hline 1854.06 & 2537.74 & 1.03 & 0.316 & 0.307 & 2.23 \\
\hline
\end{tabular}

${ }^{a}$ The specific surface area $\left(\mathrm{S}_{\mathrm{BET}}\right)$ was calculated by the BET method.

${ }^{b} \mathrm{~V}_{\mathrm{t}}$ and ${ }^{\mathrm{c}} \mathrm{V}_{\text {mire }}$ represents the total pore volume and the volume of micropores, respectively.

${ }^{\mathrm{d}} \mathrm{D}_{\mathrm{HK}}$ represents the median pore width calculated by Horvath-Kawazoe (HK).

(a)

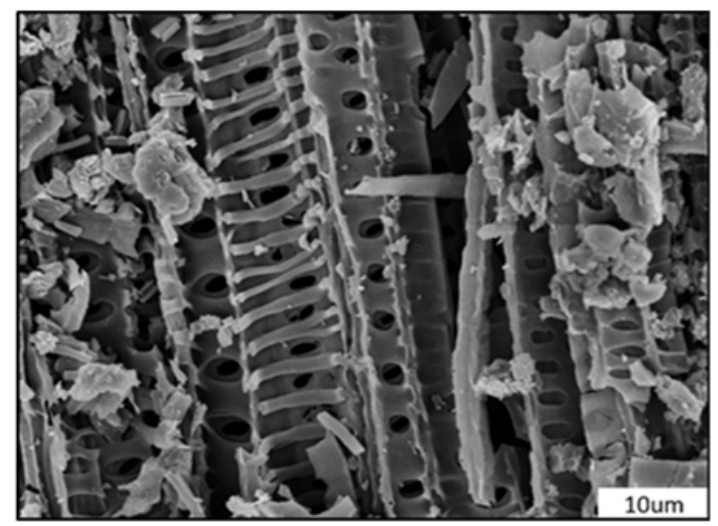

(b)
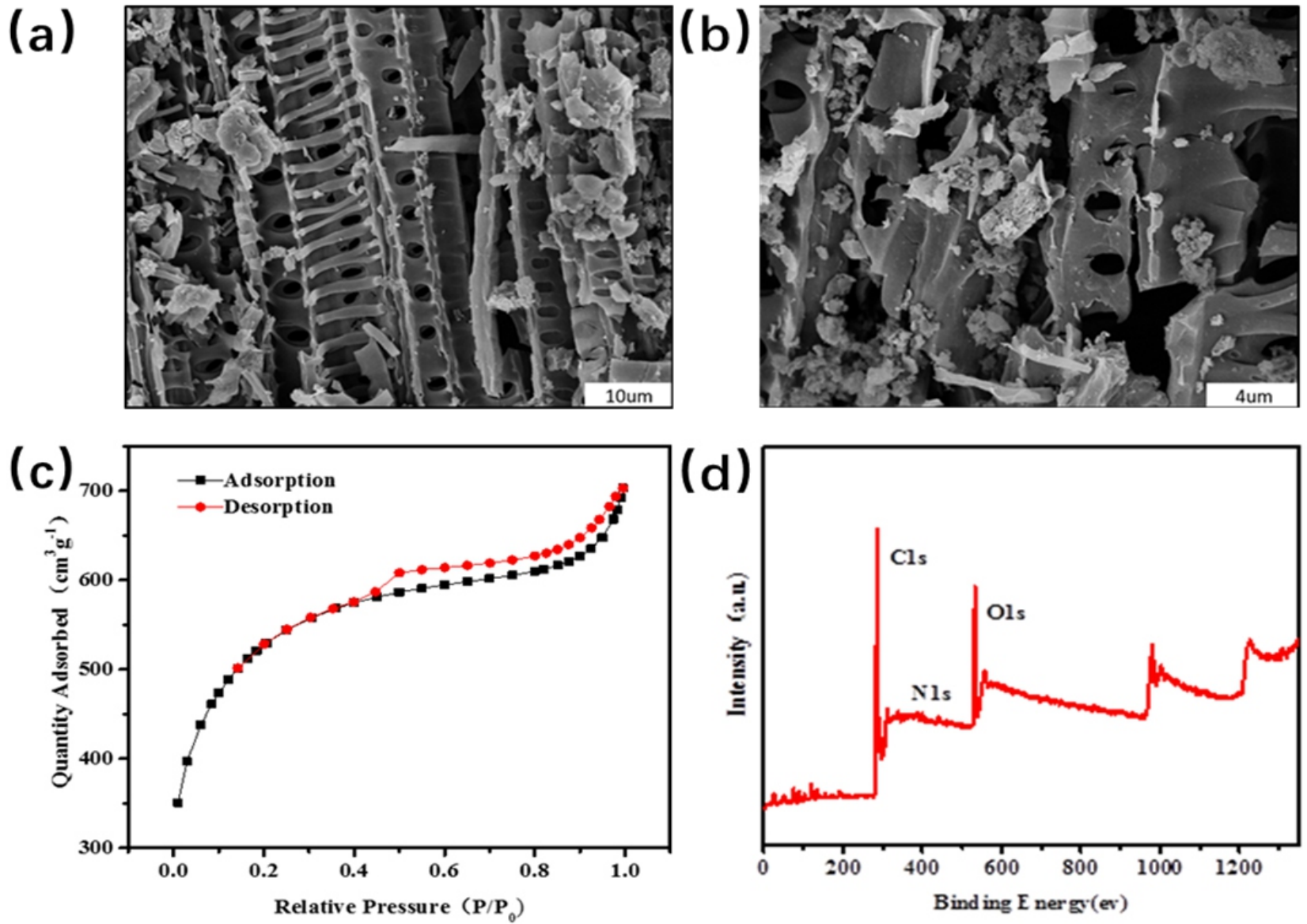

(e)
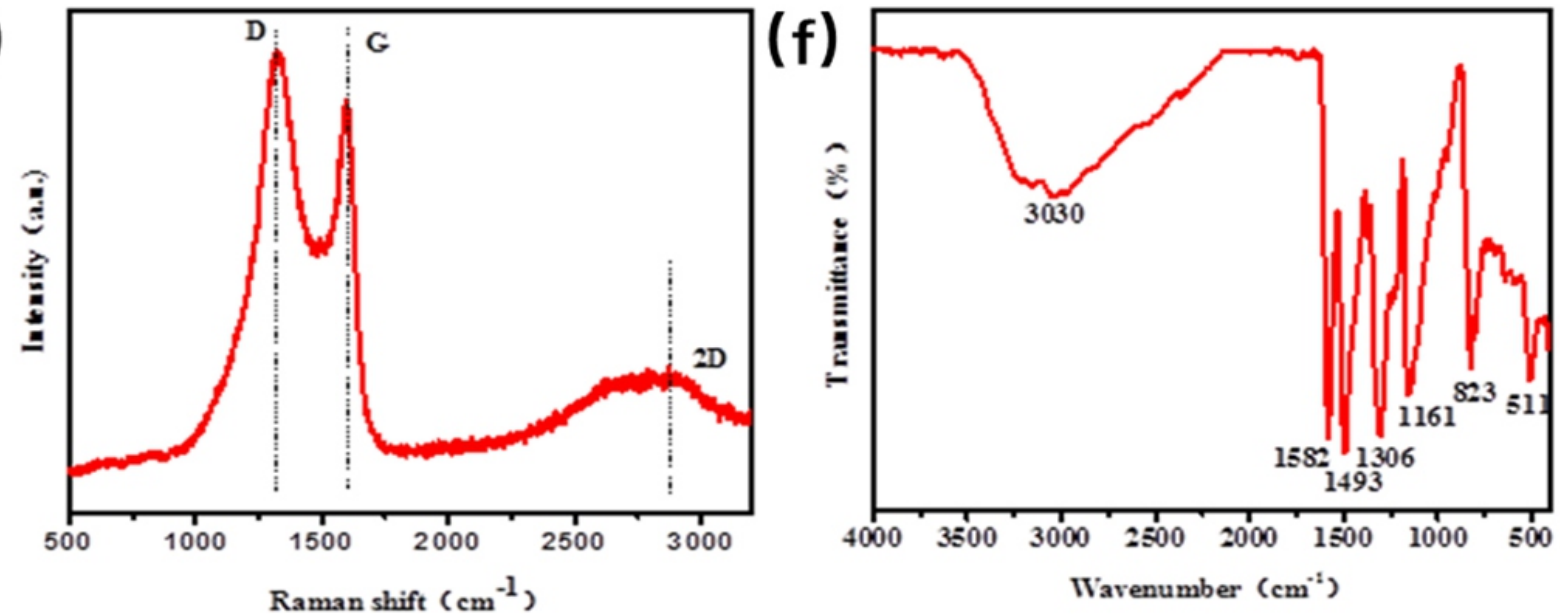

Fig. 2 Characterization of the NPCs. (a) and (b) Representative SEM images of the NPCs at magnifications of 2000 and 10000 , respectively. (c) Nitrogen adsorption-desorption isotherms. (d) XPS, (e) Raman and (f) FTIR spectra of the NPCs, respectively. 
of surface charge of carbon materials. ${ }^{34,35}$ In order to determine the elemental composition of the NPCs, elemental analysis was performed, in which $\mathrm{C}, \mathrm{O}$ and $\mathrm{N}$ contents of the NPCs were $79.11 \%, 13.69 \%$ and $2.59 \%$, respectively. Moreover, distinct peaks emerged in XPS spectrum of the NPCs (Fig. 2d), corresponding to C 1s peak ( 284.7 $\mathrm{eV})$, O 1s peak $(\sim 533.1 \mathrm{eV})$, and $\mathrm{N}$ 1s peak $(\sim 400.6 \mathrm{eV})$, respectively. The presence of $\mathrm{N}$ derived from the biomass itself, demonstrated that nitrogen-doped porous carbons could be obtained without adding secondary nitrogen source through taking the unique advantage of natural nitrogen in Euonymus japonicus leaves. The elimination of secondary nitrogen source in the present study would be beneficial for future application.

In order to further investigate the structures of the NPCs, Raman and FTIR analysis were carried out. In the Raman spectrum, two distinctive peaks at 1345 and $1594 \mathrm{~cm}^{-1}$, corresponding to D and G band, were observed (Fig. 2e). The D band is related to amorphous structures, i.e., the degree of disorder in the structures, while the $\mathrm{G}$ band is related to the graphitic order in the structures. The relative intensity ratio $\left(\mathrm{I}_{\mathrm{G}} / \mathrm{I}_{\mathrm{D}}\right)$ could be used to evaluate the graphitic degree in carbon materials. ${ }^{36}$ The $\mathrm{I}_{\mathrm{G}} / \mathrm{I}_{\mathrm{D}}$ of the NPCs was calculated to be 0.91 . In the FTIR spectrum, absorbance peaks at $(3030,1306,1161$ and 823) and 1582 $\mathrm{cm}^{-1}$, corresponding to $\mathrm{C}-\mathrm{H}$ and benzene $\mathrm{C}=\mathrm{C}$, were observed (Fig. $2 \mathrm{f}$ ).

\subsection{Adsorption of dyes by the NPCs}

The morphological structures and physio-chemical properties of the NPCs suggested that there was a good possibility for dyes to be adsorbed and trapped into the porous structures. Three model systems of dyes, including two cationic dyes (MB and $\mathrm{RhB}$ ) and one anionic dye (MO), were investigated. Color change of the solutions before and after adsorption was shown in Fig. 3. Adsorption capacity and removal efficiency are two important parameters to evaluate performance of porous carbons in removing dyes from wastewater. The dye adsorption capacities $\left(q_{e}\right)$ of the NPCs were measured under different adsorbent dosage and initial dye concentration at different contact time.

Contact time is one of the key parameters in adsorption processes, and shortening contact time is extremely important to develop costeffective procedure for industrial applications. Therefore, the effect of contact time on the adsorption of $\mathrm{MB}, \mathrm{RhB}$ and $\mathrm{MO}$ by the NPCs was examined (Fig. 4a). The adsorption was very fast at the beginning, which was due to high vacant active sites of the NPCs for the adsorption. Due to gradual saturation of the active sites, the adsorption slowly increased until reaching a flat plateau, that is, adsorption equilibrium $^{37}$. The removal efficiencies of $\mathrm{MB}$ and $\mathrm{RhB}$ were both above $99.9 \%$, while that of MO was $76.1 \%$. The adsorption capacity of the NPCs for MB and $\mathrm{RhB}$ was 506.1 and $469.5 \mathrm{mg} \cdot \mathrm{g}^{-1}$, respectively, while that for MO was $370.8 \mathrm{mg} \cdot \mathrm{g}^{-1}$. The slight difference between MB and $\mathrm{RhB}$ might be caused by the difference in molecular sizes of the two dyes. The molecular size of MB is $1.43 \mathrm{~nm} \times 0.61 \mathrm{~nm} \times 0.4 \mathrm{~nm}$, while that of $\mathrm{RhB}$ is $1.44 \mathrm{~nm} \times 1.09 \mathrm{~nm} \times 0.64 \mathrm{~nm}^{37}$. The molecular size of $\mathrm{MB}$ is smaller than that of $\mathrm{RhB}$, thus $\mathrm{MB}$ could enter the pores of the NPCs more easily.

To study the effect of the dosage of the NPCs on the adsorption processes, $\mathrm{MB}$ solutions of $100 \mathrm{mg} \cdot \mathrm{L}^{-1}$ at room temperature were individually treated with the NPCs in different amounts ranging from 10 to $40 \mathrm{mg}$ (Fig. $4 \mathrm{~b}$ ). The removal efficiencies achieved $52.7 \%$ for 10 $\mathrm{mg}, 92.3 \%$ for $20 \mathrm{mg}$, and $100 \%$ for both 30 and $40 \mathrm{mg}$, respectively. The removal efficiency increased with the dosage of the NPCs, due to the increase in the number of available adsorption sites. But the adsorption capacity decreased mainly because adsorption sites remain unsaturated, i.e., adsorbents are in the excessive state. Fig. $4 \mathrm{c}$ showed the effect of the initial dye concentration in the range from 50 to 300 $\mathrm{mg} \cdot \mathrm{L}^{-1}$. The adsorption capacities of NPCs increased from $253.2 \mathrm{mg} \cdot \mathrm{g}^{-1}$ to $626.1 \mathrm{mg} \cdot \mathrm{g}^{-1}$ for $\mathrm{MB}$, from $234.7 \mathrm{mg} \cdot \mathrm{g}^{-1}$ to $620.7 \mathrm{mg} \cdot \mathrm{g}^{-1}$ for $\mathrm{RhB}$, and from $247.5 \mathrm{mg} \cdot \mathrm{g}^{-1}$ to $367.8 \mathrm{mg} \cdot \mathrm{g}^{-1}$ for $\mathrm{MO}$, respectively. As the initial concentration increased, the adsorption capacity of the NPCs increased non-linearly until saturation. It can be seen that the NPCs showed better adsorption performance on cationic dyes $(\mathrm{MB}$ and $\mathrm{RhB})$ than the anionic dye (MO). This phenomenon could be explained by the surface charge properties of the NPCs. In the NPCs, the lone pair of the N atom can bring the negative charge due to the $\mathrm{sp}^{2}$ hybrid carbon skeleton delocalized $\pi$ system. ${ }^{34} \mathrm{~A}$ zeta-potential value of -17.9 in deionized water at neutral $\mathrm{pH}$ (Fig. 4d) indicated that the surface of the NPCs was negatively charged. Thus, the NPCs prefer to adsorb the positively charged (cationic) dyes.

\subsection{Adsorption kinetics and thermodynamics studies}

To evaluate kinetics and thermodynamics of the adsorption of $\mathrm{MB}$ in the NPCs, the experimental data at various contact times were fitted to
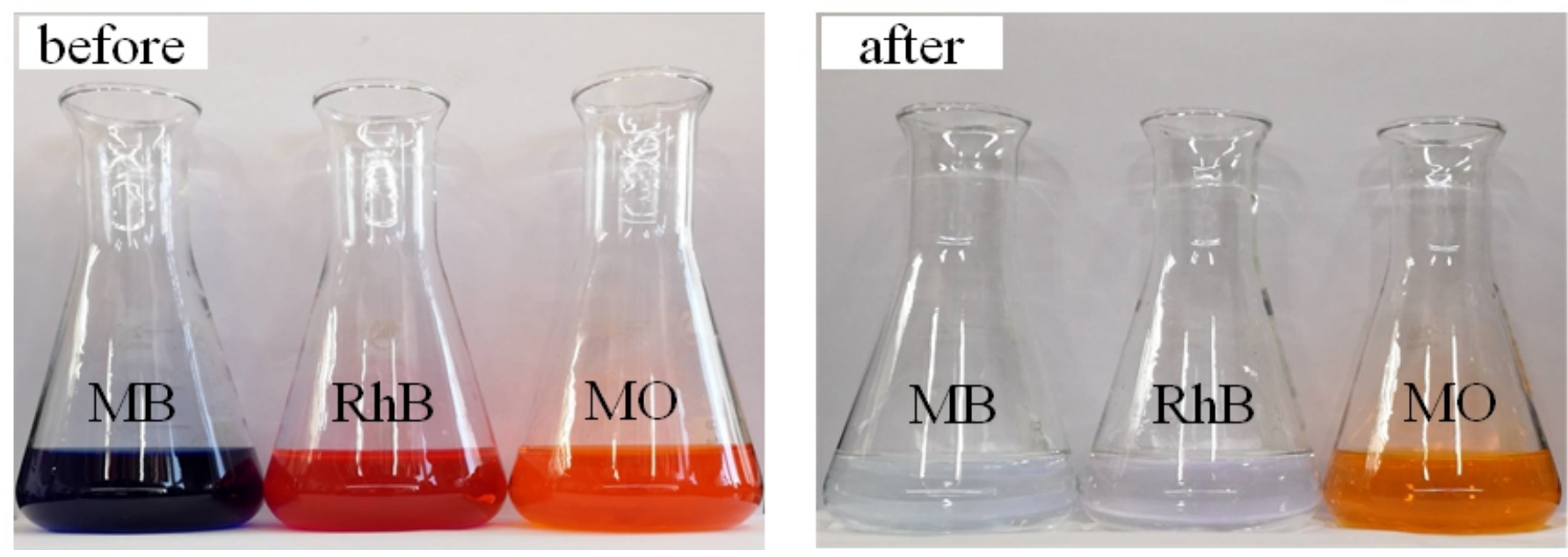

Fig. 3 Color change before and after adsorption tests. For each adsorption test, the initial concentration was 100 ppm, the volume was $100 \mathrm{~mL}$, and the dosage of the adsorbent was $20 \mathrm{mg}$. 
four different kinetic models (pseudo-first order, pseudo-second order, intra-particle diffusion and Elovich) and four isotherm models (Langmuir, Freundlich, Temkin and Dubinin-Radushkevich) ${ }^{39}$. Fig. 5 showed the plots for the four different adsorption kinetic models, and the constant values were calculated and summarized in Table S1. Theoretically, the pseudo-first order model assumes that the dye adsorption rate is directly proportional to the number of unoccupied sites. The constant $\left(k_{1}\right.$ and $\left.q_{e}\right)$ values of pseudo-first order kinetics could be calculated from the plot of $\ln \left(q_{e}-q_{t}\right)$ against $t$ (Fig. 5a). However, the calculated values of $q_{e}$ were not in a good agreement with the experimental ones, and the coefficient of determination $\left(\mathrm{R}^{2}\right)$ was relatively low. These results suggested that the pseudo-first order model was not suitable for fitting the adsorption of dyes in the NPCs.

The pseudo-second order model assumes that the dye adsorption rate is proportional to square of difference between amount of dye absorbed at time $t$ and amount of dye absorbed at equilibrium. This model is compatible with mechanism of rate-controlling step through chemisorption. The constant $\left(k_{2}\right.$ and $q_{e}$ ) values could be calculated from the plot of $\mathrm{t} / q_{t}$ against $\mathrm{t}$ (Fig. 5b). ${ }^{40}$ Considering high $\mathrm{R}^{2}$ (0.9992 for MB, 0.9990 for $\mathrm{RhB}$ and 0.9986 for $\mathrm{MO}$, respectively) and small deviation between calculated $q_{m}\left(618.42 \mathrm{mg} \cdot \mathrm{g}^{-1}\right.$ for $\left.\mathrm{MB}\right)$ and experimental $q_{e}$ $\left(626.1 \mathrm{mg} \cdot \mathrm{g}^{-1}\right.$ for MB), the experimental data showed better compliance with the pseudo-second order model, indicating existence of partial chemical adsorption through sharing or electrons exchange between dyes and the NPCs.

Another model describing chemisorption processes is the Elovich model. This model assumes that the adsorption sites are heterogeneous and display different activation energy during the adsorption process. The Elovich model follows an empirical equation, which can be simplified to a linear relationship between $q_{t}$ and $\ln t$ (Fig. 5c). ${ }^{41}$ But in the present study, the intercept of the plot did not pass through the origin. The intra-particle diffusion model assumes that during the adsorption process, the intra-particle diffusion is the rate-limiting step. The intra-particle diffusion occurs only when $q_{t}$ is linear to $t^{0.5}$ (Fig. $5 \mathrm{~d}$ ). However, in the present study, the plot showed multi-linearity correlation. These results indicated that intra-particle diffusion was not the rate-determining step in the adsorption processes of dyes in the NPCs. ${ }^{31,42}$

Fig. 6 showed the plots for the four different isotherm models. And the constant values were calculated and summarized in Table S2. The Langmuir model assumes that monolayer adsorption occurs on the adsorbent surface with identical homogeneous sites. Each site can only accommodate one atom/molecule. Once the active sites are covered, no further adsorption would take place. There are four possibilities for the
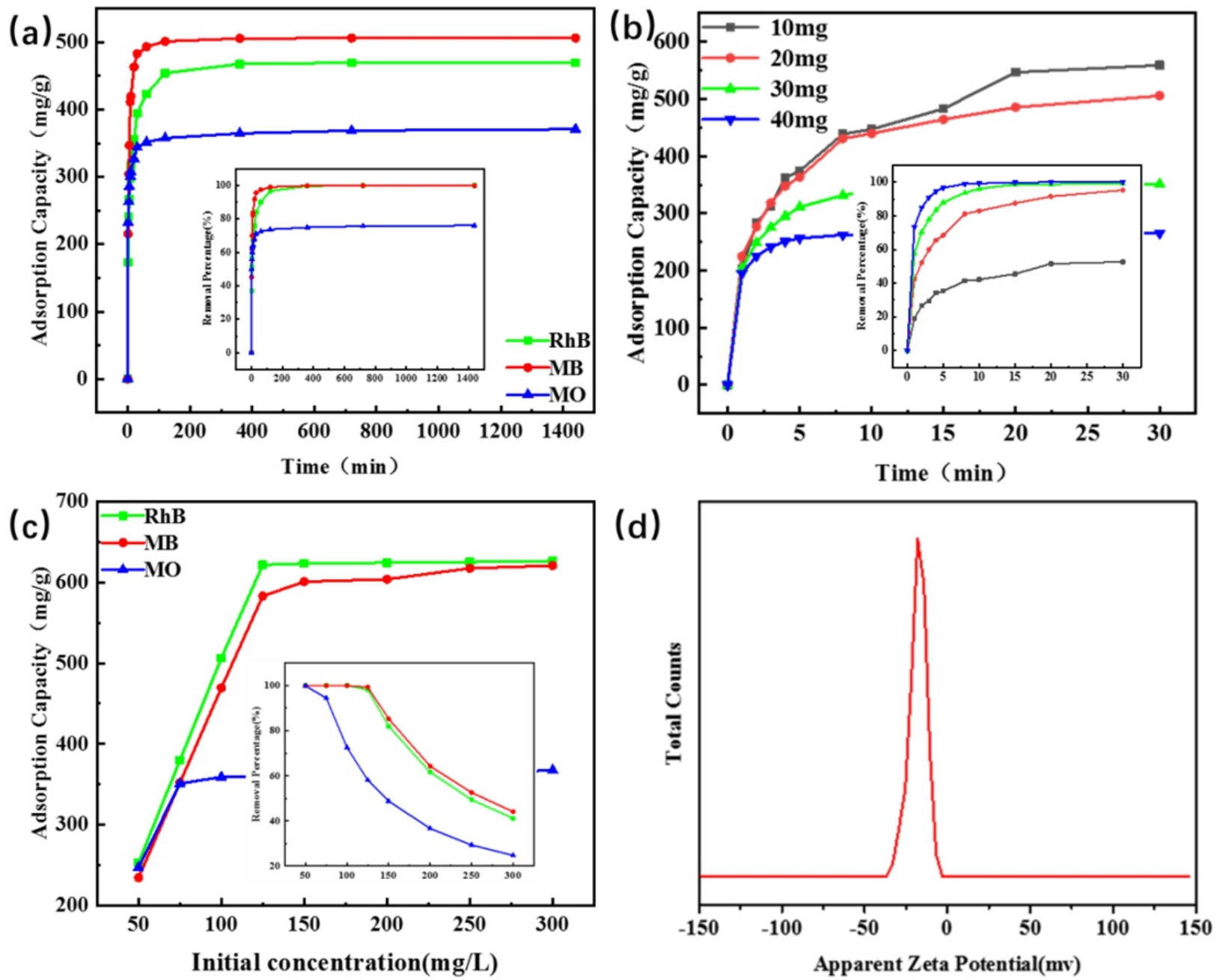

Fig. 4 Adsorption of MB, MO and RhB by the NPCs. Effect of (a) contact time, (b) adsorbent dosage and (c) initial dye concentration on the adsorption capacity and removal efficiency (inset) of the NPCs. (d) Zeta potential of the NPCs at pH 7. 
$K_{L}$, a constant related to energy of adsorption and affinity of binding in the Langmuir model: $0<K_{L}<1$, adsorption is favorable; $K_{L}>1$, adsorption is unfavorable; $K_{L}=1$, adsorption is linear; $K_{L}=0$, adsorption is irreversible. $^{43}$ The Langmuir model was found to fit the experimental data in terms of linear correlation between $c_{e} / q_{e}$ and $c_{e}$ (Fig. 6a). The close-to-1 value of $\mathrm{R}^{2}$ (0.9999 for MB, 0.9998 for RhB and 0.9999 for $\mathrm{MO}$, respectively) and small deviation between calculated $q_{m}(625.78$ $\mathrm{mg} \cdot \mathrm{g}^{-1}$ for $\left.\mathrm{MB}\right)$ and experimental $q_{e}\left(626.1 \mathrm{mg} \cdot \mathrm{g}^{-1}\right.$ for $\left.\mathrm{MB}\right)$ indicted the applicability of the Langmuir model for describing the adsorption processes on the NPCs. Therefore, the adsorption was consistent with homogeneous monolayer adsorption.

The Freundlich model is an empirical model assuming that the distribution of adsorption energy/ heat and affinity of adsorbates on a heterogeneous surface is non-uniform, and the adsorption takes place multilaterally, and the amount of adsorbed dyes increases along with pressure and concentration. In the Freundlich model, the constant $n$ and $K_{F}$ indicated the adsorption intensity and capacity, respectively. ${ }^{43}$ However, with relatively lower $\mathrm{R}^{2}$ (Fig. 6b), this model did not fit the experiment data as well as the Langmuir model. The Temkin model assumes that during the adsorption processes the interaction of adsorbate and adsorbent should be taken into considerations. Due to the adsorbate-adsorbent interactions, the adsorption heat would decrease linearly rather than logarithmically upon coverage of active sites after ignoring the extremely low and large concentrations. ${ }^{44}$ The DubininRadushkevich model assumes that the adsorbent surface is not necessarily homogeneous or with constant adsorption activation free energy. However, neither the plots of the Temkin model nor that of the Dubinin-Radushkevich model adapted for fitting the experimental data (Fig. 6c, d).

\section{Conclusions}

By using the biomass waste of Euonymus japonicus leaves as raw materials, nitrogen-doped porous carbons (NPCs) were successfully synthesized and further considered as an alternative effective adsorbent for removing pollutant dyes from wastewater. The adsorption of dyes in NPCs depended on the contact time, adsorbent dosage and initial dye concentration. The adsorption kinetics of dyes in NPCs followed the pseudo-second order model rather than the pseudo-first order, intraparticle diffusion and Elovich models, indicating existence of partial chemical adsorption. The adsorption isotherms obeyed the Langmuir model rather than the Temkin, Freundlich and Dubinin-Radushkevich models, implying homogeneous monolayer adsorption. The maximum adsorption capacities of the NPCs for MB, RhB and MO were 626.1, 620.7 and $370.8 \mathrm{mg} \cdot \mathrm{g}^{-1}$, respectively. The excellent adsorption performance of the NPCs could mainly be attributed to their large surface area $\left(1854.06 \mathrm{~m}^{2} \cdot \mathrm{g}^{-1}\right)$, suitable pore size distribution (with both
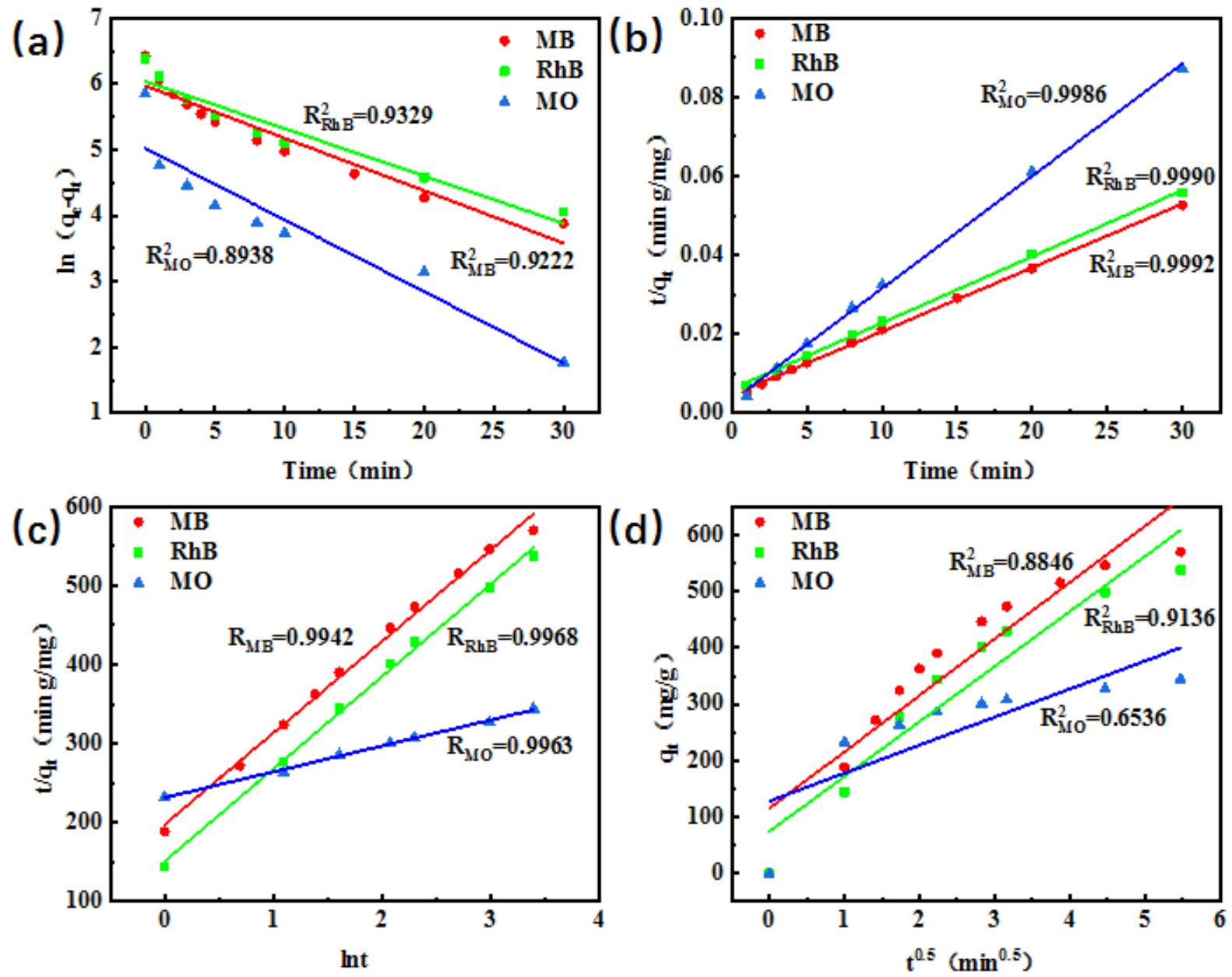

Fig. 5 The kinetics study on the adsorption processes. Plots of (a) $\ln \left(q_{e}-q_{t}\right)$ against $t$ for pseudo-first order model, (b) $t / q_{t}$ against $t$ for pseudo-second order model, (c) $q_{t}$ against $l n t$ for Elovich model and (d) $q_{t}$ against $\mathrm{t}^{0.5}$ for intra-particle diffusion model. 

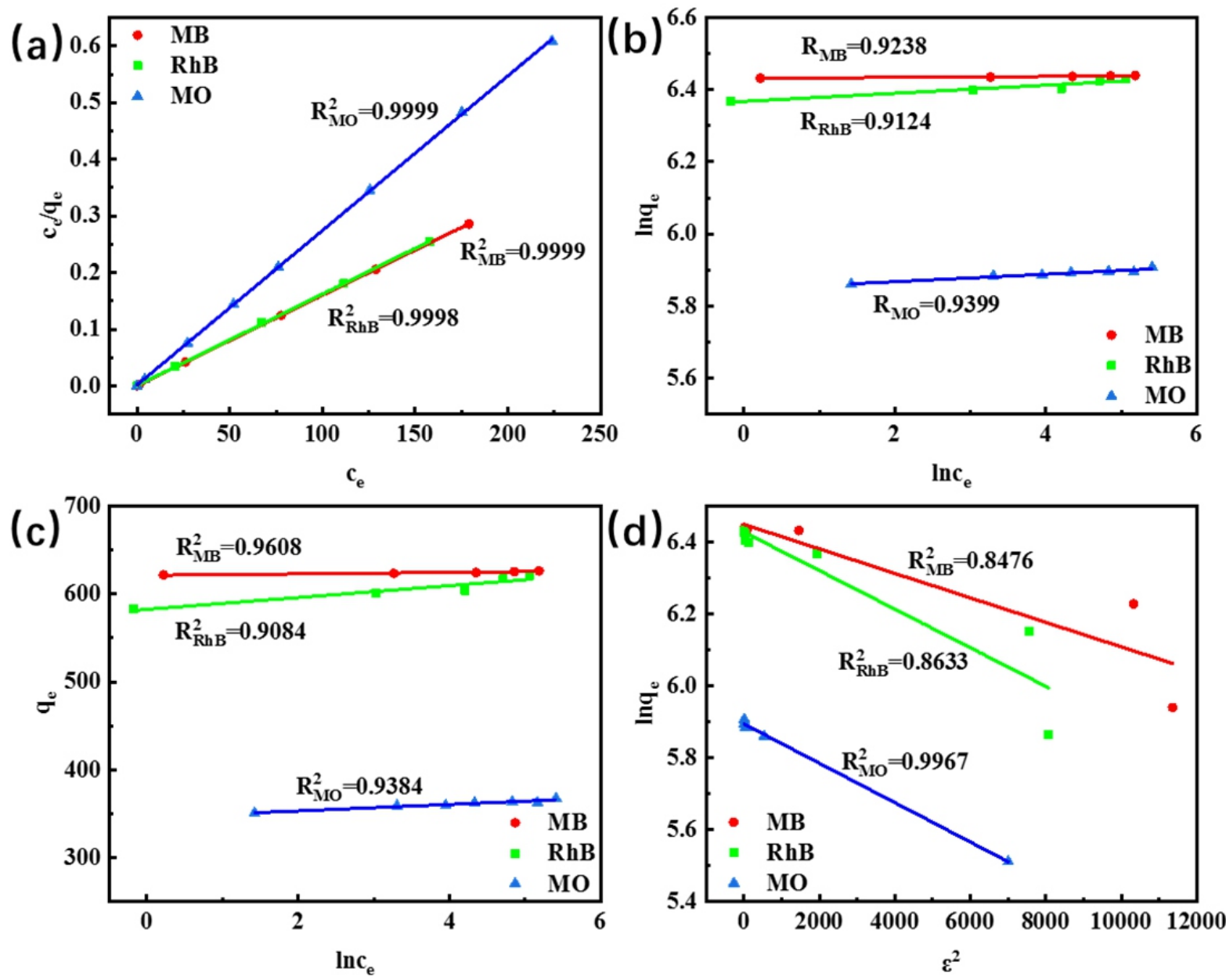

Fig. 6 The isotherm study on the adsorption processes. Plots of (a) Langmuir model, (b) Freundlich model, (c) Temkin model and (d) DubininRadushkevich model.

mesopores and micropores) and nitrogen self-doping (2.59\%). All these features of the NPCs demonstrated that it is a promising low-cost and high efficient candidate for removing pollutant dyes from wastewater and reducing environmental problems related to disposal of biomass waste (leaves).

\section{Declarations of interest}

The authors declare no conflict of interest

\section{Acknowledgements}

This work was supported by the National Key Research Program of China [2016YFA0201701/2016YFA0201700], NSF of China [21625601] and the Ministry of Science and Technology [2015DFG92090, 2017YFC0211400].

\section{References:}

1. S. Hajati, M. Ghaedi, F. Karimi, B. Barazesh, R. Sahraei and A. Daneshfar, J. Ind. Eng. Chem., 2014, 20, 564-571.

2. E.Brillas and C. A. Martínez-Huitle, Appl. Catal. B , 2015, 166- 167, 603643.

3. M. T. Yagub, T. K. Sen, S. Afroze and H. M. Ang, Adv. Colloid Interface Sci., 2014, 209, 172-184.
4. I. Ali, Chem. Rev., 2012, 112, 5073-5091.

5. H. C. Tao, H. R. Zhang, J. B. Li and W. Y. Ding, Bioresour. Technol., 2015, 192, 611-617.

6. S. Li, S. Hu, W. Jiang, Y. Liu, Y. Zhou, J. Liu and Z. Wang, J. Colloid Interface Sci., 2018, 530, 171.

7. X. Xiang, F. Pan and Y. Li, Eng. Sci., 2018, 3, 77-83.

8. Y. Huang, X. Zeng, L. Guo, J. Lan, L. Zhang and D. Cao, Sep. Purif. Technol., 2018, 194, 462-469.

9. L. Zhang, Q. Zhang, H. Xie, J. Guo, H. Lyu, Y. Li, Z. Sun, H. Wang and Z. Guo, Appl. Catal. B-Environ., 2017, 201, 470-478.

10. Y. Cao, J. Huang, Y. Li, S. Qiu, J. Liu, A. Khasanov, M. A. Khan, D. P. Young, F. Peng, D. Cao, X. Peng, K. Hong and Z. Guo, Carbon., 2016, 109, 640-649.

11. Y. Cao, J. Huang, X. Peng, D. Cao, A. Galaska, S. Qiu, J. Liu, M. A. Khan, D. P. Young, J. E. Ryu, H. Feng, N. Yerra and Z. Guo, Carbon., 2017, 115, 503-514.

12. M. Ghaedi, B. Sadeghian, A. A. Pebdani, R. Sahraei, A. Daneshfar and C. Duran, Chem. Eng. J., 2012, 187, 133-141.

13. Y. Kismir and A. Z. Aroguz, Chem. Eng. J., 2011, 172, 199-206.

14. L. Lv, Y. Huang and D. Cao, Appl. Surf. Sci., 2018, 456, 184-194.

15. K. Y. Foo and B. H. Hameed, Microporous Mesoporous Mater., 2012, 148, 191-195.

16. V. O. Njoku, M. A. Islam, M. Asif and B. H. Hameed, Chem. Eng. J., 2014, 251, 183-191.

17. G. Skouteris, D. Saroj, P. Melidis, F. I. Hai and S. Ouki, Bioresour. Technol., 
2015, 185, 399-410.

18. K. Y. Foo and B. H. Hameed, Chem. Eng. J., 2012, 184, 57-65.

19. C. Saucier, M. A. Adebayo, E. C. Lima, R. Cataluna, P. S. Thue, L. D. T. Prola, M. J. Puchana-Rosero, F. M. Machado, F. A. Pavan and G. L. Dotto, J. Hazard. Mater., 2015, 289, 18-27.

20. Y. Zhao, F. Fang, H.M. Xiao, Q.P. Feng, L.Y. Xiong and S.Y. Fu, Chem. Eng. J., 2015, 270, 528-534.

21. M. E. Fernandez, B. Ledesma, S. Roman, P. R. Bonelli and A. L. Cukierman, Bioresour. Technol., 2015, 183, 221-228.

22. G. G. Choi, S. J. Oh, S. J. Lee and J. S. Kim, Bioresour. Technol., 2015, 178, 99-107.

23. P. Hadi, M. Xu, C. Ning, C. Sze Ki Lin and G. McKay, Chem. Eng. J., 2015, 260, 895-906

24. A. Reffas, V. Bernardet, B. David, L. Reinert, M. B. Lehocine, M. Dubois, N. Batisse and L. Duclaux, J. Hazard. Mater., 2010, 175, 779-788.

25. M. A. Ahmad and N. K. Rahman, Chem. Eng. J., 2011, 170, 154-161.

26. J. Kazmierczak-Razna, B. Gralak-Podemska, P. Nowicki and R. Pietrzak, Chem. Eng. J., 2015, 269, 352-358.

27. X. Wang, X. Zeng and D. Cao, Eng. Sci., 2018, 1, 55-63.

28. Y. Huang, D. Wu, D. Cao and D. Cheng, Int. J. Hydrogen Energy, 018, 43, 8611-8622.
29. L. Tan and B. H. Hameed, J. Taiwan Inst. Chem. E., 2017, 74, 25-48.

30. Y. Foo and B. H. Hameed, Chem. Eng. J., 2010, 156, 2-10.

31. Autaa and B. H. Hameed, Chem. Eng. J., 2011, 171, 502-509.

32. Y. Gor, M. Thommes, K. A. Cychosz and A. V. Neimark, Carbon., 2012, 50, 1583-1590.

33. Wen, J. Di, Y. Zhao, Y. Wang, L. Jiang and J. Yu, Chem. Sci., 2013, 4, 4378.

34. Ma, X. Shao and D. Cao, J. Mater. Chem., 2012, 22, 8911-8915.

35. Zhang, F. Sun, Z. Shen and D. Cao, J. Mater. Chem. A, 2014, 2, 1287312880.

36. C. Ferrari and D. M. Basko, Nat. Nanotechnol., 2013, 8, 235-246.

37. Benadjemia, L. Millière, L. Reinert, N. Benderdouche and L. Duclaux, Fuel Process. Technol., 2011, 92, 1203-1212.

38. Baccar, P. Blánquez, J. Bouzid, M. Feki and M. Sarrà, Chem. Eng. J., 2010, 165, 457-464.

39. Maneerung, J. Liew, Y. Dai, S. Kawi, C. Chong and C. H. Wang, Bioresour. Technol., 2016, 200, 350-359.

40. A. Berman, Fuel, 2015, 151, 83-90.

41. J. D. Low, Chem. Rev., 1960, 60, 267-312.

42. Xu, Y. Lv, X. Zeng and D. Cao, Chem. Eng. J., 2017, 323, 502-511.

43. Ignatowicz, Int. J. Heat Mass Transfer., 2011, 54, 4931-4938.

44. Aharoni and M. Ungarish, J. Chem. Soc., Faraday Trans., 1977, 73, 456-464. 